\title{
Apontamentos sobre o fazer etnográfico: agruras e prazeres de uma pesquisadora-torcedora nas imediações de um estádio de futebol
}

\section{RESUMO}

Neste trabalho, buscamos relatar, problematizar e instigar inquietações pertinentes a uma pesquisa etnográfica, abordando as agruras e prazeres de uma pesquisadoratorcedora, inerentes aos desdobramentos de uma investigação nas imediações do estádio Arena do Grêmio, na cidade de Porto Alegre/RS. Procuramos dar ênfase às questões de gênero e à sensação de insegurança urbana, que figuram o território como um cenário hostil à pesquisadora-torcedora, tecendo experiências de sujeição e enfrentamentos. Portanto, tratamos das especificidades de uma pesquisa de campo realizada por uma mulher, em território futebolístico e periférico da cidade. Ademais, abordamos os 'sabores' de se realizar a investigação, sejam eles agradáveis, pelas satisfações suscitadas na dupla pertença, ou desagradáveis, pelos desapontamentos vividos, estabelecendo barreiras e contornos específicos, que implicaram nos recursos possíveis e/ou disponíveis no campo. Tratamos ainda, de instigar os pares a potencializar as discussões que envolvam as desigualdades entre gêneros no campo científico.

PALAVRAS-CHAVE: Etnografia; Análise de gênero; Futebol; Território sociocultural
Daiane Grillo Martins

Mestra em Educação Física Universidade Federal de Pelotas, Escola Superior de Educação Física, Pelotas, Brasil

daia.martins82@gmail.com

https://orcid.org/0000-0001-5363-1795

Raquel da Silveira

Doutora em Ciências do Movimento Humano

Universidade Federal do Rio Grande do Sul,

Departamento de Educação Física,

Fisioterapia e Dança,

Porto Alegre, Brasil raqufrgs@gmail.com

Ohttps://orcid.org/0000-0001-8632-0731

Alan Goularte Knuth

Doutor em Epidemiologia Universidade Federal do Rio Grande, Instituto de Educação,

Rio Grande, Brasil alan_knuth@yahoo.com.br - Chttps://orcid.org/0000-0002-2030-5747 
Notes on ethnographic research: issues and pleasures of a female researcher-fan in the surroundings of a football stadium

\begin{abstract}
In this article, we seek to describe and analyze concerns related to ethnographic research, pointing out the issues and pleasures of a female researcher-fan during an inquiry in the surroundings of the Arena do Grêmio stadium in Porto Alegre, Brazil. We emphasize gender issues and the perception of urban insecurity, picturing the territory as a hostile scenario for a female researcher, weaving experiences of subjection and confrontations. Therefore, we deal with the specifics of field research carried out by a woman in football territory and the suburbs of the city. Furthermore, we address the flavors of carrying out the investigation, either pleasant ones due to the satisfaction aroused by double belonging, or unpleasant due to the disappointments experienced, establishing specific barriers and contours, which imply in the possible and/or available resources in the field. We also encourage peers to enhance discussions concerning inequalities between genders in the scientific field.
\end{abstract}

KEYWORDS: Ethnography; Gender analysis; Soccer; Sociocultural territory

\title{
Apuntes sobre el trabajo etnográfico: penurias y placeres de una investigadora-hincha en las inmediaciones de un estadio de fútbol
}

\section{RESUMEN}

En este trabajo buscamos reportar, problematizar e instigar inquietudes pertinentes a una investigación etnográfica, abordando las privaciones y placeres de una hincha investigadora, inherentes al desarrollo de una investigación en las cercanías del estadio Arena do Grêmio, en la ciudad de Porto Alegre/RS. Intentamos enfatizar las cuestiones de género y el sentimiento de inseguridad urbana, que configuran el territorio como un escenario hostil a una hincha investigadora, tejiendo experiencias de sometimiento y enfrentamientos. Por tanto, nos ocupamos de la especificidad de una investigación de campo realizada por una mujer, en el fútbol y territorio periférico de la ciudad. Además, nos acercamos a los 'sabores' de realizar la investigación, sean agradables, por las satisfacciones planteadas en la doble pertenencia, o desagradables, por las decepciones vividas, estableciendo barreras y contornos específicos, que implicaban lo posible y / o recursos disponibles en el campo. También tratamos de incitar a los pares a mejorar las discusiones que involucran desigualdades entre géneros en el campo científico.

PALABRAS-CLAVE: Etnografía; Análisis de género; Fútbol; Territorio sociocultural 


\section{INTRODUÇÃO}

Mulheres no universo científico brasileiro, assim como nos diversos contextos sociais, estão sujeitas a tensionamentos de legitimação. Nascimento e Dourado (2015) apontam que na produção de conhecimento ainda há disparidade entre homens e mulheres, fato que "é reflexo de um contexto social e relações de poder construídas, mesmo com os avanços, em que as posições prestigiosas são predominantemente dos homens" (p. 2). Contudo, é perceptível que o número de cientistas mulheres vem aumentando, já que onde há relações de poder, também há resistência (FOUCAULT, 2018). E como nos diversificados campos sociais, as mulheres vêm conquistando espaços de legitimação, embora ainda precisem avançar nas relações de igualdade de gênero. Por isso, se faz necessário falar especificamente sobre mulheres e o cotidiano científico.

Neste trabalho, abordamos questões disparadas a partir de uma pesquisadora ${ }^{1}$ que realizou uma investigação etnográfica nas imediações de um estádio de futebol, pertencente ao clube ao qual é torcedora. Trata-se de um conteúdo pertinente às inquietações fomentadas na tríade 'ser pesquisadora', 'ser torcedora' e 'ser mulher', que foram suscitadas pela pesquisadora-torcedora a partir de suas vivências no campo. Tais inquietações foram compartilhadas com os demais autores deste trabalho, ao longo do processo de pesquisa, procedendo nos apontamentos aqui expostos.

Conforme Hall (2005), ao referir-se à multiplicidade de identidades, elucida que os indivíduos assumem "identidades diferentes em diferentes momentos, identidades que não são unificadas ao redor de um 'eu' coerente" (p. 13). Nessa perspectiva, sinalizamos também que a indissociabilidade 'ser mulher', 'ser pesquisadora' e 'ser torcedora' contemplou agruras, assim como prazeres à pesquisadora-torcedora. Nessas identidades, a cada ida a campo, eram tecidas experiências com 'sabores', a partir do que era observado, sentido e vivido.

As sensações de se pesquisar um campo que mexe com sua paixão torcedora suscitaram sabores desejáveis, mas também contemplaram experiências inóspitas, já que os acontecimentos do jogo agiram diretamente na torcedora. Consideramos ainda que, além dos enfrentamentos travados no próprio ambiente acadêmico, a questão de ser mulher no campo que é majoritariamente composto por homens, associada à sensação de insegurança atribuíram especificidades à pesquisa.

Para Elias (1999), o/a cientista precisa olhar para os acontecimentos sociais considerando os seus processos de longa duração, que abarcam o desenvolvimento de várias gerações, contextualizados no plano histórico. Portanto, inicialmente, procuramos contextualizar brevemente

\footnotetext{
${ }^{1}$ Primeira autora deste trabalho, que realizou a pesquisa de campo. A segunda autora acompanhou o processo de investigação, participando da elaboração de estratégias para o trabalho de campo e também analítico. Já o terceiro autor é o orientador dessa pesquisa e contribuiu significativamente às reflexões deste trabalho.
} 
a pesquisa que originou este trabalho, explanando seus trajetos teórico-metodológicos. Por seguinte, tratamos os prazeres e as agruras suscitadas na imersão etnográfica, contemplando relatos e reflexões sobre a pesquisadora-torcedora do/no campo investigado e com isso, buscando suscitar inquietações.

\section{APRESENTAÇÃO DA PESQUISA}

$\mathrm{Na}$ sociedade brasileira, o futebol trata-se de uma prática esportiva de grande visibilidade social, já que "apresenta uma incrível capacidade de atrair um grande número de indivíduos com gestos e estilos de vida tão variados” (JAHNECKA, 2010, p. 67). No contexto clubístico, os estádios de futebol se configuram como palco do espetáculo constituído pelas obras (o jogo), os artistas (jogadores) e o público, que são os torcedores (DAMO, 2005). Embora os estádios sejam considerados o palco do espetáculo, sinalizamos que as manifestações torcedoras não são pertinentes somente ao interior destes espaços. O espaço-tempo vivido ${ }^{2}$ do torcer também é pertinente a outros territórios, como lares, bares, ruas e o lado de fora dos estádios, nas suas imediações, nos tempos pré, durante e pós-jogo.

Portanto, existem várias formas de se manifestar o torcer que ultrapassam as dimensões espaciais e temporais dos estádios, como, por exemplo, os espaços-tempos inerentes às interações proporcionadas pelas transmissões de televisão e internet. Partindo desta prerrogativa, realizamos uma pesquisa etnográfica na zona periférica norte do perímetro urbano da metrópole Porto Alegre, capital do estado do Rio Grande do Sul, Brasil. Nesse contexto, buscamos compreender como ocorrem as relações de apropriação do espaço das imediações da Arena do Grêmio ${ }^{3}$, provenientes das manifestações torcedoras, no período que antecede o horário dos jogos no estádio. Também investigamos como esse acontecimento compõe a vida de moradores e moradoras das imediações do estádio e de outras regiões ${ }^{4}$.

Contemplando as ferramentas etnográficas, foram realizadas observações, conversas informais, caminhadas em torno do estádio, resultando na elaboração de diários de campo. A

\footnotetext{
2 "Enquanto espaço-tempo vivido, o território é sempre múltiplo, diverso e complexo [...] Podemos então afirmar que o território, imerso em relações de dominação e/ou de apropriação sociedade-espaço, desdobra-se ao longo de um continuum que vai da dominação político-econômica mais 'concreta' e 'funcional' à apropriação mais subjetiva e/ou 'cultural-simbólica'" (Haesbaert, 2007, p.21).

${ }^{3}$ Estádio inaugurado no ano de 2012, pertencente ao Grêmio Foot-Ball Porto Alegrense. O clube foi fundado na cidade de Porto Alegre, no ano de 1903.

${ }^{4}$ Dissertação de mestrado da primeira autora, no Programa de Pós-Graduação em Educação Física da Universidade Federal de Pelotas (UFPEL), Brasil. Desta pesquisa, já está publicado um artigo na Revista Movimento (MARTINS; KNUTH, 2020a) e outro na Revista Fulia (MARTNS; KNUTH, 2020b).
} 
pesquisadora também utilizou imagens fotografadas e filmadas através de smartphone, de uso pessoal, como instrumentos de auxílio para a confecção dos diários do campo. A fase empírica se iniciou no segundo semestre de 2018, de 23 de setembro a 02 de dezembro, totalizando sete idas acampo, em dias de jogos oficiais do Grêmio Foot-Ball Porto Alegrense, no Campeonato Brasileiro (cinco jogos) e Copa Libertadores da América (dois jogos) ${ }^{5}$.

A prioridade de espaço-tempo de observações ficou reservada à extensão da Avenida Padre Leopoldo Brentano (principal via de acesso ao estádio), no período que antecede os jogos. O campo de investigação teve suas extremidades demarcadas pelos estabelecimentos Bar do Tricolor até o Bar do Ito, na Avenida AJ Renner (perpendicular à avenida principal), totalizando aproximadamente 650 metros de distância. Pontuamos que as imediações da Arena estão para além do território pertinente à pesquisa, no entanto, a fim de possibilitar uma imersão mais profunda, foi necessário delimitar o espaço. Portanto, além de um recorte temporal, também houve um recorte espacial, considerando dois aspectos específicos: o cenário de permanência de maior número de torcedores/as e demais sujeitos do campo e também por proporcionar à pesquisadora-torcedora maior sensação de segurança para circular nesses espaços.

Endossamos que dependendo dos acontecimentos durante o processo de pesquisa, que vão desde o deslocamento até o campo e os fatos lá ocorrentes, o tempo estimado de permanência a cada imersão teve variações de uma a quatro horas. Isso porque, se tratando de pesquisa qualitativa, o/a cientista social tem como preocupação básica "a estreita aproximação dos dados, de fazê-lo falar de forma mais completa possível, abrindo-se à realidade social para melhor aprendê-la e compreendê-la" (MARTINS, 2004, p. 292).

A pesquisadora partia ora do Rio Grande, cidade ao sul do estado do Rio Grande do Sul, onde residia na época da pesquisa, localizada a mais de $300 \mathrm{~km}$ do campo de pesquisa, ora já estava em Porto Alegre. Os deslocamentos até o campo ocorreram por meio de excursão com um grupo de torcedores/as gremistas, da cidade do Rio Grande, que possui ônibus próprio para promover excursões a jogos e eventos do clube em Porto Alegre e outras cidades. Também por meio de ônibus intermunicipal, coletivo da capital, que circula por entre os bairros da cidade ou via condução de aplicativo. Em seis dos sete jogos ocorridos, a pesquisadora entrou no estádio para torcer, momentos antes de começar a partida, ou ainda, logo após o começo. Em uma noite de Libertadores da América, a permanência em campo ocorreu também durante o horário do jogo.

\footnotetext{
5 Esses jogos totalizam os que aconteceram no período da pesquisa de campo, com exceção de um jogo pelo Campeonato Brasileiro, em que a pesquisadora não pôde estar presente nas imediações da Arena.
} 


\section{PRAZERES E AGRURAS DA PESQUISADORA-TORCEDORA}

Aqui buscamos relatar, refletir e instigar inquietações sobre questões pertinentes a esta pesquisa etnográfica, abordando as agruras e prazeres vivenciados pela pesquisadora-torcedora. Sua relação com o campo investigado começa antes do processo da pesquisa. A inauguração da Arena do Grêmio aconteceu no final de 2012, mas a história do clube começa em 1903, ano de sua fundação. Muitas histórias se entrelaçam à história do Grêmio, ao longo de sua existência, o que é justamente o caso da história desta pesquisadora-torcedora.

Uma mulher do interior do estado, que desde a infância, com maior intensidade durante a adolescência, nutre a paixão pelo clube da capital, inclusive demarca esse sentimento de pertencimento clubístico ${ }^{6}$ na pele, através de uma tatuagem. É uma torcedora que vai pisar pela primeira vez na antiga casa do Grêmio aos 30 anos, para assistir a um jogo do campeonato brasileiro no estádio Olímpico Monumental ${ }^{7}$. É uma mulher que de tanto gostar de futebol, começa a cursar de Educação Física, no ano de 2009 e realiza seu trabalho de conclusão de curso investigando torcedoras que frequentam um estádio de futebol em sua cidade ${ }^{8}$. É uma pesquisadora que ingressa no mestrado em Educação Física, com uma proposta de pesquisa que se origina da observação através de uma experiência enquanto torcedora, no ano de 2016, na ida à nova casa de seu clube: a Arena do Grêmio.

Numa tarde de domingo, ocorreu o primeiro contato de horas prolongadas de permanência nas imediações da Arena, participando pela primeira vez de uma excursão com um grupo de torcedores/as, partindo da cidade de Rio Grande/RS. O jogo começava às 16 horas, mas o ônibus chegou a Porto Alegre por voltas das 10 horas, pois os/as torcedores/as também planejaram fazer um churrasco de almoço. Logo ao descer do veículo e começar a caminhar, alguns aspectos chamaram a sua atenção sobre as manifestações torcedoras e as relações estabelecidas com o contexto local.

Como, além de torcedora, ali também estava presente uma pesquisadora, logo o processo investigativo começou a suscitar o desejo da compreensão e a perceber um potente campo de pesquisa. Ao longo do dia, estas observações só foram fomentando pistas sobre a vida social que pulsa nas imediações da Arena, em espaços como os bares, as casas, as ruas, os ônibus de

\footnotetext{
${ }^{6}$ Entendemos o torcer de acordo com Damo (2002), sendo o mesmo que pertencer "o que significa, literalmente, fazer parte, tomar partido, assumir certos riscos e vivenciar excitações agradáveis ou frustrações" (p. 12). O torcer se estabelece a partir do engajamento emocional, das ligações afetivas de cada sujeito com determinado clube.

${ }^{7}$ O Olímpico foi o estádio do Grêmio até a inauguração da Arena.

${ }^{8}$ Ver: Apontamentos sobre as manifestações do "ser torcedora" do Sport Club São Paulo (MARTINS; SILVERA; FREITAS, 2014).
} 
torcedores/as vindos/as do interior do Rio Grande do Sul e também de outros estados e os lugares onde se concentram os vendedores/as ambulantes. Naquele dia, a torcedora-pesquisadora saiu do estádio com o gosto desagradável da derrota de seu time, mas com certo sabor instigante, do nascimento de uma ideia sobre o que pesquisar no pretendido mestrado.

A partir do contexto exposto, introduzimos as agruras do campo, abordando a mulher pesquisadora a qual nos referimos, já que foi através desta afirmativa que introduzimos o trabalho. Além das questões pertinentes ao próprio ambiente acadêmico, procuramos explanar aqui, acontecimentos durante sua imersão no campo referentes à inter-relação ser mulher - sensação de insegurança, em que as suas sensações suscitadas se traduzem em 'sabores' que não são agradáveis e tampouco desejáveis.

Sobre a sensação de insegurança, Baierl (2008), elucida que

Trata-se de um medo cíclico, motivado por situações reais conhecidas, principalmente através da mídia ou pela fala cotidiana do crime, independente da possibilidade real dele vir acontecer ou de ter sido vivenciado diretamente pela pessoa, familiares ou vizinhança. Trata-se de um medo imaginário, de algo difuso, mas que aparece como possibilidade real ao sujeito e ele passa acreditar nisso. É essa possibilidade imaginada como real - geradora de insegurança - que faz emergir um medo imaginário que conduz as pessoas a alterarem significativamente seus ritmos e a dinâmica da vida cotidiana, podendo gerar reações iguais ou mais violentas daquela imaginada. Isso alimenta e é alimentado por aquilo que denominamos "indústria do medo" e pela descrença nos sistemas de segurança pública legalmente instituídos (p. 143).

Já na primeira ida a campo a pesquisadora-torcedora, mesmo que bastante motivada por estar chegando numa etapa tão desejada de sua pesquisa, pôde perceber que os dias e noites de permanência no campo não seriam um "mar de rosas". Isso fica evidenciado no diário de campo, num dia chuvoso e, por isso, de pouco movimento de público que permanece nas imediações do estádio no período pré-jogo:

Conforme fui tomando conhecimento do entorno do estádio, tirava algumas fotos e realizava as anotações. Como alguns setores do estádio têm menor circulação de público, eu acabava tirando as fotos rapidamente, já que alguns torcedores/as e pessoas que moram em Porto Alegre avisaram para tomar cuidado com a ocorrência de furtos naquela região (DIÁRIO DE CAMPO I, 23/09/2018).

Mesmo com os 'sabores' desejáveis de uma pesquisadora, que vão sendo degustados nas descobertas, as agruras provocadas pela sensação de insegurança são perceptíveis também no diário de uma noite de Libertadores da América, competição sul-americana de bastante prestígio no universo do futebol de alto rendimento: 
Impressiono-me com a quantidade de bares, mercearias e lancherias existentes, em que a grande maioria faz alusão ao Grêmio, seja no nome e/ou nas cores do estabelecimento. Do meio para o final da avenida também chamou atenção a quantidade de casas que se transformam em estacionamentos: são calçadas, garagens e pátios, que são guardados por mulheres e homens que ficam no centro da rua chamando por seus clientes que chegam nos seus veículos, até onde o movimento de torcedores ocupando as ruas os deixam ir. Não são apenas centros de comércio, mas também lugares sede de torcidas organizadas, como o Grêmio Democrático, da Torcida Jovem [...] São churrasqueiras nos canteiros, nas calçadas, nas garagens, nos pátios. São isopores e mais isopores de bebidas. Os bares, os churrascos, enfim, os encontros se estendem também pelas ruas perpendiculares à Padre Brentano. Cheguei a adentrar algumas dessas ruas, mas como a circulação de público era menor e a atmosfera de afastamento da avenida principal me causou certa insegurança de andar por ali sozinha, resolvi voltar à Padre Brentano (Diário de campo II, 2/10/2018).

Os relatos nos remetem à sensação de insegurança da pesquisadora-torcedora, mesmo em ocasiões com maior quantidade de público, já que "a 'rua', quer como espaço urbano quer como categoria discursiva, é porventura o cenário contemporâneo onde mais se projeta o 'sentimento de insegurança"” (CUNHA; DURÃO, 2011, p. 63). Para as autoras, trata-se de "uma rotação histórica das formas e lugares dos medos públicos, focalizados primeiro na cidade como espaço predatório e cristalizados depois em novas franjas de marginalidade, mas agora transmutando-se discursivamente em "sentimentos de insegurança"” (p. 57). Esse sentimento, pertinente aos espaços públicos do campo investigado, orientou ações circunstanciais que impuseram limites às descobertas e registros específicos, o que implicou não somente nas experiências que marcam a pesquisadora-torcedora, mas nos próprios desfechos da pesquisa.

A sensação de insegurança alimentada pela indústria do medo afeta as mulheres de forma particular, quanto ao aspecto sensação de vulnerabilidade nos territórios urbanos, já que além da questão do medo coletivo que assola o tecido social, de modo geral, as mulheres também carregam o estigma de ser alvo prioritário de violência sexual. Assim, a cidade "expressa a lógica da reprodução das desigualdades e da segregação, impondo a nós - homens e mulheres - a viver de forma diferenciada esse ambiente territorial, de viver e conviver com o espaço e dinâmica da cidade" (ALVES, 2014, p. 26).

Tratamos ainda das peculiaridades de ser mulher num campo de pesquisa predominantemente constituído por homens e marcado pela relação de dominação, pois os esportes (em especial o futebol) se consolidaram práticas que foram criadas por homens e para homens. Desse modo, as mulheres tiveram que conquistar seu espaço nesses ambientes, pois segundo Goellner (2003), o público feminino conseguiu conquistar maior visibilidade a partir das décadas iniciais do século XX. Especificamente no Brasil, as mulheres ainda enfrentaram a proibição legal de sua inserção enquanto praticantes de algumas modalidades esportivas, inclusive o futebol, por 
meio da "interdição imposta pelo Estado Novo de Getúlio Vargas, regulamentada pela ditadura militar em 1965 e revogada somente no ano de 1979" (KNIJNIK, 2003, p. 20). Todavia, a ocupação dos espaços esportivos, pelas mulheres, ocorreu, mesmo que constituído por um processo lento.

No que tange ao futebol, quando perde sua fidalguia, muitas mulheres são proibidas e desestimuladas a frequentar os espaços futebolísticos, enquanto público apreciador dessa modalidade ${ }^{9}$ praticada por homens (COSTA, 2006). Como a assistência não estava mais "exclusiva aos homens e mulheres da elite, os outros extratos da população também passaram a frequentar esse espaço de lazer, com a finalidade de torcer pelo time ao qual pertencem" (CAMPOS, 2010, p. 30). Assim, a popularização dessa prática pode ser considerada fator fundamental na redução da participação das mulheres nos espaços futebolísticos.

Através da vigilância que há atualmente a respeito da violência em estádios, é notável a frequência crescente de mulheres nos estádios de futebol, em dias de jogos. Contudo, ainda é pertinente a contestação da mulher conhecedora e pertencente ao universo futebolístico. Tal fato é referenciado por Costa (2006), ao mencionar sobre a crescente incorporação feminina em páginas da Internet voltadas ao interesse em futebol, manifestando seus posicionamentos e comportamentos:

Essa incorporação [...] apresenta alguns obstáculos e um dos mais importantes refere-se à legitimação da mulher como indivíduo que não apenas é capaz de nutrir sentimentos de pertencimento clubístico, mas que também pode interessar-se pelo jogo de futebol, compreendê-lo em seus aspectos técnicos e táticos (p. 2).

Portanto, no universo futebolístico, mulheres precisam "ir contra uma série de representações que fomentaram a ideia de que as mulheres e o futebol atuam em campos opostos" (COSTA, 2006, p. 3).

Assim, considerando as imediações da Arena, em dias de jogos, como território pertinente ao público torcedor, que são em predominância homens, expomos que foi na quarta ida a campo que aconteceu um dos fatos mais marcantes da experiência da pesquisadora-torcedora, contextualizado no trecho do diário de campo a seguir:

A circulação pela avenida já estava bastante dificultosa. Era muita gente parada nas calçadas e no meio da rua [...] Em frente ao bar dos Borrachos havia muita gente [...] procurei atravessar do meio da rua para a calçada, para que lá de cima pudesse ter uma vista melhor e realizar uma filmagem [...] fui passar entre um grupo de torcedores que estavam entre quatro ou cinco membros, bebendo e reunidos em volta a uma caixa de bebidas que estava no chão. No momento em que fui

${ }^{9}$ Capellano (1999) elucida que “foram as mulheres, aliás, que consagraram a expressão 'torcer'. Como não ficava bem para uma dama se descabelar, gritar, chorar, com seu time de coração, elas levavam para os estádios pedaços de pano, os quais torciam durante as partidas para aliviar a tensão. O habito as fez ficar conhecidas como 'torcedoras' e não demorou muito para o termo ser adotado para designar todos aqueles que compareciam com frequência às partidas no intuito de incentivar as equipes" (p. 28 e 29). 
atravessar por entre o grupo, senti que um deles tocou com a mão à minha nádega. Fiquei na dúvida se havia sido propositalmente. E ainda tentando passar, escuto um deles dizer "com tanto lugar pra passar", enquanto outro deles se posicionava a minha frente como se não quisesse colaborar para minha passagem. Daí então, novamente, a mão toca à minha nádega. E agora, a certeza de que o toque era proposital, imediatamente um sentimento de nojo e indignação tomou conta de mim. Não era a primeira vez que isso acontecia comigo. Em festas noturnas já houve outros episódios e a minha reação, como em outros momentos, foi quase que instintiva. Voltei-me ao agressor (já que considero esse ato uma forma de agressão) e também retribuí com agressão, aplicando um soco e um chute [...] A reação do grupo e do agressor foi de espanto. Talvez nunca esperasse que ao molestar uma mulher, poderia receber em troca outro tipo de agressão (DÁRIO DE CAMPO IV, 30/10/2018).

Para Foucault (2018), as formas de dominação, nas relações de poder, se constituem através do assujeitamento. Nesse contexto, os gêneros são produções de desigualdade que acontecem "nas e pelas relações de poder" (LOURO, 1997, p. 41). Conforme Soares (2006),

A sociedade em que vivemos se caracteriza por relações de dominação, e nela a sexualidade, atitudes, comportamentos e sujeitos específicos são designados a partir do sexo primordial, o do homem. O regime masculino, que se estabeleceu ao longo dos tempos vem ditando a posição e os papéis de homens e mulheres, cujos valores e padrões de comportamento, também, são legitimados e consagrados socialmente (p. 63).

Contudo, o ato de abuso de um homem sobre o corpo de uma mulher extrapola a relação consentida e como em toda relação de poder há possibilidade de resistência, a reação da pesquisadora se caracteriza como um ato de revide à dominação masculina. É pertinente ponderar que a mulher a qual nos referimos, que menciona sua ação "quase que instintiva", também é uma mulher que nasceu e se cresceu na zona periférica de uma cidade portuária, num núcleo familiar de baixa renda constituído somente por mulheres (ela, sua mãe, sua avó e sua irmã). Que sua infância foi constituída pelo brincar na rua, em que a maior parte dos amigos/vizinhos que compartilhavam as brincadeiras era meninos. É também uma mulher que desde a adolescência jogava futebol na escola e praticou diversas modalidades de lutas, mais especificamente a capoeira, que pratica desde os 17 anos. Portanto, a essa ação instintiva atribuímos uma noção não biológica, mas de suas construções sociais, das formas de se constituir enquanto mulher.

A partir dessas considerações, ao tratarmos de gênero e mais especificamente, das formas de se constituir mulher, sinalizamos que a questão da distinção está para além de uma constituição binária homem x mulher. Ela também está "carregada da afirmação da diferença entre as mulheres" (LOURO, 1997, p. 45). Conforme a autora, não há um 'ser masculino' e um 'ser feminino' e sim diversas formas de feminilidades e masculinidades que operam na formação das identidades de homens e mulheres, de acordo com os contextos sociais que cada sujeito vivencia. Portanto, 
podemos dizer que "a concepção fortemente polarizada dos gêneros esconde a pluralidade existente em cada um dos polos" (LOURO, 1997, p. 48).

Dessa forma, há de se considerar que mulheres não são tão somente mulheres, elas são mulheres pertencentes a determinada classe econômica, etnia, religião, sexualidade, etc. Logo, são sujeitos de identidades plurais que "se interferem mutuamente, se articulam; podem ser contraditórias; provocam, enfim, diferentes "posições"” (LOURO, 1997, p. 51). Cada mulher, de forma única, se constitui mulher, apresentando-se relativamente deslocada do padrão hegemônico sobre o que é ser feminino.

Portanto, essa reação da pesquisadora-torcedora, enquanto mulher que enfrenta estes homens que se colocam numa situação abusiva sobre o corpo feminino, é uma reação de uma mulher que se constitui enquanto mulher através de suas experiências de vida e os contextos culturais que lhe são pertinentes. Por isso, pode ser que se fosse outra mulher passando por uma situação semelhante, a forma de resistir se efetivasse de outra maneira ou nem acontecesse.

Em outra ocasião, no entanto, entendemos que a pesquisadora-torcedora produz menos força na relação de poder, ao sujeitar-se quando troca de roupa para não chamar atenção, movida pelo desconforto que a situação estava lhe causando, conforme está exposto no trecho a seguir:

Eu também estava de blusa amarela, carregando minha camisa do Grêmio na bolsa. E o fato é que, de uma maneira como não tinha acontecido nas imersões de campo anteriores, $\mathrm{o}$ assédio dos homens que por mim passavam estava frequente. Mesmo que nenhum outro tenha me tocado, as "piadinhas" aconteceram, ao longo da avenida. E isso foi mais um fato que me deixou bastante desconfortável [...] Até que, ao me dirigir às calçadas da Arena, para filmar a entrada dos torcedores no estádio, mais dois episódios de assédio acontecem [...]. Bastante incomodada com aquela situação e já com certo receio porque permaneceria na rua durante todo o jogo, tirei a minha camisa tricolor da bolsa e coloquei por cima da camisa amarela, considerando a hipótese de que eu poderia estar chamado atenção pelo decote, pela cor da blusa ou ainda por não estar caracterizada como torcedora. E o que eu mais estava desejando naquele momento era parecer invisível, já que a vontade mesmo era de ir embora, mas que isso eu não faria, considerando meu compromisso com a pesquisa (DIÁRIO DE CAMPO IV, 30/10/2018).

Para Winkin (1998), os diários de campo se configuram como essencial instrumento, por meio de suas funções catártica (íntima, emotiva), empírica, reflexiva e analítica. Portanto, a pesquisadora-torcedora revela, em seu diário, as angústias daquela noite de Libertadores. São sentimentos documentados no instrumento da pesquisa, vinculados ao fato de ser mulher que se remetem à segregação de gêneros, ainda que para termos conhecimento disso não precisemos recorrer à comprovação científica, pois basta estar no mundo para saber que esse tipo de situação é vivenciado por mulheres. O trecho do diário também nos direciona para o discurso ainda latente de que o assédio também pode ser culpa das mulheres, conforme seus comportamentos. 
Nos aponta Foucault (2018) que "a verdade é deste mundo; ela é produzida nele graças a múltiplas coerções e nele produz efeitos regulamentados de poder" (p. 52) e o discurso de que existem comportamentos apropriados especificamente para mulheres produz efeitos de verdade. Assim, chamamos a atenção, pois mesmo que no episódio anterior a pesquisadora-torcedora tenha demonstrado resistência, agora ela se dá por convencida, apelando para si a verdade de um comportamento apropriado. O fato de trocar de roupa para se tornar invisível aos olhares masculinos, elucida que no corpo da mulher ainda circulam discursos de verdade que demarcam a dominação masculina.

Assim, consideramos que ao interpelar e ser interpelada pela verdade que usar uma blusa menos decotada e de cor menos "chamativa" seria um comportamento mais adequado, naquele contexto, é uma forma de sujeição que "consiste precisamente nessa dependência fundamental de um discurso que nunca escolhemos, mas que, paradoxalmente, inicia e sustenta nossa ação" (BUTLER, 2019, p. 10). Assim, seja pela interpelação, seja pela produtividade discursiva, “"sujeição' significa tanto o processo de se tornar subordinado pelo poder quanto o processo de se tornar sujeito" (p. 10).

Toda essa atmosfera vivenciada pela pesquisadora-torcedora conduz ao sentimento de medo e sensação de vulnerabilidade por ser mulher e estar sozinha no campo. Cunha e Durão (2011), atentam que "o medo não é pré-discursivo. É produzido como categoria em função das atividades de agências, poderes e saberes que lhe moldam o conteúdo através da forma como trabalham, refinam, testam e reportam esse medo" (p. 56). Complementa ainda que "o medo reconfigura-se no formato fluido das vulnerabilidades dos Estados, mas também dos seres humanos e dos corpos" (p. 56). Isso fica evidente no diário de campo em que a sua autora aponta seu olhar para as questões de gênero no campo, ainda naquela noite de Libertadores:

O grupo que ocupava o espaço do bar D' Julia tinha característica típica daquela do contexto geral do território: a maioria era de homens jovens, mas também havia homens mais velhos, mulheres junto aos homens e também em grupos de duas ou três. A única mulher sozinha era eu e considerando tudo que já havia vivido naquele dia, optei por parar próxima a um grupo de mulheres, para causar a impressão de que estivesse junto delas [...] Ao voltar para o segundo tempo, dois homens se posicionaram logo atrás de mim e percebi que me olhavam e comentavam alguma coisa. Talvez fosse a curiosidade de me ver sozinha por ali, mas novamente considerando o ar de hostilidade que encontrei no campo, aquela situação me deixou mais desconfortável. Eu comecei então a pensar que o jogo, apesar do adversário estar levando perigo ao gol do Grêmio, que o resultado daquele jogo já estaria encaminhado. Inclusive eu já fazia planos para o jogo da final, com um misto de alegria enquanto torcedora e angustiada enquanto pesquisadora, pelos desprazeres que a noite de Libertadores me proporcionou. $\mathrm{E}$ essa angustia foi crescendo ao adiantar da hora e com o tempo se armando para chuva. Comecei a projetar que se esperasse o apito final, poderia não conseguir 
transporte porque seria muita gente saindo do estádio e solicitando, ao mesmo tempo. Então o medo de ficar sozinha até o estender da madrugada no campo foi maior que o desejo existente desde o planejamento, de ficar até depois que o jogo acabasse. Foi aí que decidi acessar o aplicativo e a condução chegou em poucos minutos. Considerei também que com o tempo que estava se armando, a maioria das pessoas iria embora, já que logo choveria. Era 34 minutos de partida quando entrei no carro (DIÁRIO DE CAMPO IV, 30/102018).

Retomamos à inter-relação ser mulher e sensação de insegurança que conduziu contornos específicos à pesquisa. Naquela noite, a pesquisadora-torcedora tinha por intuito permanecer no campo após o final do jogo, mas não foi isso que ocorreu. Além disso, ela deixou o campo sob atmosfera de classificação do Grêmio e acabou não presenciando o oposto, já que logo que deixou as imediações do estádio, o time argentino fez dois gols. Esse resultado, fatidicamente, desclassificou a equipe brasileira da competição. Ressaltamos que para a pesquisadora-torcedora, estar presente no campo, sob a atmosfera da tragédia poderia ter agregado dados peculiares à pesquisa e essa foi uma das questões que mais agruras lhe causou: a possibilidade de perder dados que poderiam contribuir ao estudo.

Aproveitamos essa passagem justamente para explanar as agruras e prazeres no que tange as nuances entre a familiaridade e estranhamento do campo. Alertou Velho (1978), ao tematizar a investigação antropológica do contexto social familiar, que "o que sempre vemos e encontramos pode ser familiar, mas não é necessariamente conhecido e o que não vemos e encontramos, pode ser exótico, mas, até certo ponto, conhecido" (p. 126). A questão pertinente é a possibilidade de se “estar acostumado com uma certa paisagem social onde a disposição dos atores me é familiar (...) no entanto, isso não significa que eu compreenda a lógica de suas relações” (p. 128).

Portanto, o campo investigado configura um mundo social que a pesquisadora-torcedora, conhece sem conhecer, bordando-a no tecido da "dupla pertença" (GOMES; MENEZES, 2008). Desse modo, consideramos a investigadora também uma nativa do campo, já que o território das imediações da Arena se apresenta como um espaço pertinente ao pertencimento de torcedoras e torcedores gremistas. $\mathrm{O}$ misto das tensões da dupla-pertença se expressam no relato do segundo diário de campo:

Esperando o ônibus dos Borrachos para embarque rumo à segunda ida a campo, agora para um jogo de Libertadores. Pela primeira vez eu estaria pisando em um território de Libertadores da América. Cerveja na mão, enquanto espero o ônibus, em um posto de gasolina e camisa do Grêmio na bolsa, na intenção de não me identificar enquanto torcedora, no campo. Talvez isso seja mesmo uma preparação interna de distanciamento e de demarcação que a identidade pesquisadora me exige para uma pesquisa etnográfica, já que a identidade torcedora também se faz pertinente. Por isso, a camisa eu não deixei de carregar, já que a reserva na excursão foi solicitada com ingresso para o jogo [...] Embora o trabalho interno de distanciamento esteja surtindo efeito e isso eu percebi já na primeira ida a campo, 
mas também nesta, ao me deparar já no alento do Grill ${ }^{10}$, apenas observando atentamente o contexto e não me motivando a participar (DIÁRIO DE CAMPO II, 2/10/2018).

Para a pesquisadora-torcedora, o campo suscitou um misto de estranhamento e familiaridade, pois "vestir a capa de etnólogo[a] é aprender a realizar uma dupla tarefa que pode ser grosseiramente contida nas seguintes fórmulas: (a) transformar o exótico no familiar e/ou (b) transformar o familiar em exóticos" (DAMATTA, 1978, p. 4). O estranhamento se fez presente desde a primeira imersão, mesmo que, enquanto torcedora já tenha vivenciado o território, em período que antecede o jogo. No entanto, ao pisar nas imediações da Arena enquanto pesquisadora, o olhar para o território é um olhar que se diferencia daquele de torcedora. Logo, as sensações agradáveis e também as desagradáveis possuem suas frequências também moduladas na dupla pertença.

As imersões no campo foram marcadas pelas angústias, satisfações, alegrias, tristezas, apontamentos e desapontamentos. Ao finalizar o diário de campo IV, a pesquisadora-torcedora transporta para o instrumento toda frustração vivida naquela noite de Libertadores, onde quase nada saiu conforme o planejado. Não foi uma experiência fácil nem para os olhos da pesquisadora e nem para o coração da torcedora que só conseguiu chegar nas imediações da Arena bem depois do horário estipulado, devido contratempos no transporte. Na chuva forte, ainda teve que socorrer um motoclista que se acidentou diante do carro que a transportava de volta para a residência a qual estava hospedada e ainda contou com a desclassificação do Grêmio na competição:

Cheguei ao apartamento do meu amigo toda molhada e totalmente arrasada. Ainda incrédula com tudo que havia acontecido naquele dia. Tomei um banho quente que não foi suficiente para lavar o que estava impregnado. Era um desânimo tão grande que a vontade era de não voltar mais a campo. Custei muito a dormir e quando acordei, tudo que eu queria era não falar sobre o que havia ocorrido, não escutar e ler nada sobre o jogo e não escrever absolutamente nada. Era uma pesquisadoratorcedora em estado de luto (DIÁRIO DE CAMPO IV, 30/10/2018).

Como nem só de agrura foram as idas a campo, a pesquisadora-torcedora, que na noite da quarta imersão custou a dormir e no dia posterior possuía o sentimento de luto, teve na sua seguinte permanência um sabor mais agradável, pois "naquela noite, o sono foi tranquilo, marcado pela vitória importante do Grêmio rumo à classificação para Libertadores do ano que vem e pelo acolhimento que o campo [...] proporcionou neste dia (DIÁRIO DE CAMPO V, 11/11/2018). Gomes e Menezes (2008) ao suscitar reflexões sobre a ambiguidade entre "estar" no campo ou

${ }^{10} \mathrm{O}$ alento do Grill é um rito dos torcedores dos borrachos do trovão, que na estrada, quando o ônibus faz parada no Paradouro Grill, os membros já descem com os instrumentos pra realizar os cânticos da torcida geral do grêmio, no espaço do estacionamento. 
"ser" do campo, mencionam que "qualquer imersão no campo traz a possibilidade de emergência de sentimentos" (p. 17).

Logo, a mescla estar e ser do campo também entrelaça sensações relacionadas à pesquisa e ao torcer e essa indissociabilidade fica evidente ao longo dos diários, pois frequentemente há relatos de sensações e sentimentos que ora nos remetem à pesquisadora e ora à torcedora. Endossamos este apontamento, com as palavras da pesquisadora-torcedora, referindo-se aos momentos finais de sua segunda ida a campo, ao mencionar as satisfações com o resultado do jogo e com as análises de uma cientista social:

Sentei na poltrona do ônibus exausta, pelas longas horas envolvida com a pesquisa e com o jogo. Os pés já não eram tão molhados quanto na primeira ida a campo, mas estavam doloridos. Afinal, foram horas de caminhada e já se passavam quase doze horas, desde que entrei no ônibus rumo ao Humaitá. No entanto, a sensação de contentamento se sobressaiu ao cansaço. Ao ouvir o motor do veículo sendo acionado, me flagrei com um sorriso no canto da boca, ao perceber a alegria dos/das torcedores/as que entravam no ônibus e também a minha, pela goleada do Grêmio. Esse sorriso também estava mesclado pela satisfação, proporcionada pelo encontro da pesquisadora com toda vida social pulsante das imediações da Arena, em dia de Libertadores (DIÁRIO DE CAMPO II, 2/10/2018).

Assim, podemos dizer que não há como dissociar a pesquisadora da torcedora e que o misto de sentimentos, sensações e emoções provenientes do estar e ser no/do campo se constituíram como inter-relações constantes e pertinentes ao processo dessa pesquisa antropológica, já que a pesquisadora é componente da pesquisa e, portanto, dotada de carne, nervos e sentidos (WACQUANT, 2002). A cada ida a campo a pesquisadora-torcedora se deparava com um território específico, que nunca era idêntico ao anterior e nem ao seguinte, que é líquido, pois suas organizações não mantém sua forma por muito tempo, "se decompõem e se dissolvem mais rápido que o tempo que leva para moldá-las e, uma vez reorganizadas, para que se estabeleçam" (BAUMAN, 2007, p. 7) e que, por isso, dificilmente seria sentido da mesma forma em toda imersão.

\section{CONSIDERAÇÕES}

Nas ondulações entre o familiar e o estranhamento, de se fazer pesquisa de campo nas imediações de um estádio de futebol em dias de jogos, buscamos dar ênfase aos aspectos relativos às questões de gênero e à sensação de insegurança urbana, que figuram o território investigado, tecendo experiências de sujeição, travando barreiras e, portanto, contornando o desenvolvimento da pesquisa. O fato de uma pesquisadora estar imersa no campo de investigação, que se caracteriza 
como espaço público urbano predominantemente constituído por homens, em uma zona periférica de uma metrópole brasileira, conduziu a pesquisa por caminhos específicos.

Esses trajetos foram traçados pela transversalidade indissociável ser cientista mulher e sensação de insegurança, que caracterizam as agruras do campo. A experiência da pesquisadoratorcedora nos remete às peculiaridades de se fazer pesquisa que suscitam não somente agruras, mas também satisfações relacionadas aos aspectos científicos e também do sentimento de pertencimento clubístico. Logo, o campo possui variações de 'sabores', ora mais, ora menos agradáveis, causados a uma pesquisadora-torcedora.

Propomos-nos a sinalizar que uma cientista social é sujeito inerente à pesquisa e que esta é dotada de carne, nervos e sentidos, portanto, a pesquisa também é composta de sensibilidade. Através da sua constituição de sujeito, suas experiências de vida e visão de mundo se transportam para o universo acadêmico e se entrelaçam à suas produções científicas. Na dupla pertença de estar e ser no/do campo de uma pesquisa etnográfica, a mulher da qual tratamos não se posiciona somente como torcedora ou pesquisadora, mas se firma como pesquisadora-torcedora. Assim, apresentamos relatos e reflexões que possuem seus sabores, desfechos e pertinência de identidades que não se dissociam no processo da pesquisa.

Procuramos fomentar inquietações sobre as peculiaridades de uma investigação realizada por uma mulher, em território futebolístico e periférico de uma metrópole brasileira, aqui pensada com a contribuição de mais um homem e uma mulher. Bauman (2003) aponta que a liberdade está para além da ausência de restrições e que para realizarmos coisas, precisamos de recursos. Logo, a liberdade de se fazer pesquisa de campo também se determina por fatores transversais, que implicam nos recursos possíveis e/ou disponíveis no processo investigativo.

Ao concluirmos, sinalizamos que as questões de gênero sejam problematizadas e enfrentadas por toda a sociedade, não somente por mulheres e para mulheres. Especificamente, no mundo acadêmico, buscamos instigar os pares a potencializar as discussões que envolvam as especificidades das pesquisas realizas por mulheres e as implicações da desigualdade entre gêneros no campo científico. Precisamos pensar juntos/as. 


\section{REFERÊNCIAS}

ALVES, Mércia. (In) segurança pública e violência urbana: desafios e perspectivas. Salvador, 2014. Disponível em: http://www.bibliotecadigital.abong.org.br/handle/11465/351. Acesso em: 14 ago. 2021.

BAIERL, Luzia Fátima. Medo social: dilemas cotidianos. Ponto \& vírgula, São Paulo, V. 3, p. 138-151, 2008. Disponível em:

https://200.144.145.36/index.php/pontoevirgula/article/view/14246. Acesso em: 11 ago. 2021.

BAUMAN, Zygmunt. Comunidade: a busca por segurança no mundo atual. Rio de Janeiro: Jorge Zahar, 2003.

BAUMAN, Zygmunt. Tempos líquidos. Rio de Janeiro: Jorge Zahar, 2007.

BUTLER. Judith. A vida psíquica do poder: teorias da sujeição. $1^{\mathrm{a}}$ ed. Belo Horizonte: Autêntica Editora, 2019.

CAMPOS, Priscila Augusta Ferreira. Mulheres torcedoras do Cruzeiro Esporte Clube presentes no Mineirão. 2010. Dissertação (Mestrado em Lazer) - Escola de Educação Física, Fisioterapia e Terapia Ocupacional, Universidade Federal de Minas Gerais, Belo Horizonte, 2010.

CAPELLANO, Renata. O torcer de futebol e a imprensa especializada. Juíz de Fora: UFJF, 1999.

COSTA, Leda Maria da. Maria-chuteiras x torcedoras "autênticas": Identidade feminina e futebol.

XII Encontro Regional de História. ANPUH-RJ, 2006. Disponível em:

https://comunicacaoeesporte.files.wordpress.com/2017/02/torcedorasleda-maria-da-costa.pdf.

Acesso em: 10 ago. 2021.

CUNHA, Manuela Ivone; DURÃO, Susana. Os sentidos da segurança: ambiguidades e reduções. Etnográfica, Portugal, vol. 15 (1), p. 53-66, 2011. Disponível em:

https://journals.openedition.org/etnografica/790. Acesso em: 09 jul. 2021.

DAMATTA, Roberto. O Ofício de Etnólogo, ou como Ter "Anthropological Blues". In: NUNES, Edson de Oliveira. (org.) A Aventura Sociológica. Rio de Janeiro: Zahar, 1978. p. 23-35.

DAMO, Arlei Sander. Futebol e identidade social: uma leitura antropológica das rivalidades entre torcedores e clubes. Porto Alegre: Universidade/ UFRGS, 2002.

DAMO, Arlei Sander. Senso de jogo. Esporte e Sociedade, Rio de Janeiro, n. 1, p. 1-43, 2005.

Disponível em: https://periodicos.uff.br/esportesociedade/article/view/47796. Acesso em: 03 ago. 2021.

ELIAS, Norbert. Introdução à Sociologia. Lisboa: edições 70, 1999.

FOUCAULT, Michel. Microfísica do poder. $7^{\mathrm{a}}$ ed. Rio de Janeiro/ São Paulo: Paz e Terra, 2018. 
GOELLNER, Silvana Vilodre. O esporte e a espetacularização dos corpos femininos. In: Revista Labrys: Estudos Feministas, nº 4, 2003. Disponível em:

https://www.labrys.net.br/labrys4/textos/silvana1.htm. Acesso em: 10 de jun. 2021.

GOMES. Edlaine de Campos; MENEZES, Rachel Aisengart. Etnografias possíveis: “estar” ou "ser" de dentro. Ponto Urbe, n³, São Paulo, 2008.

Disponível em: https://journals.openedition.org/pontourbe/1748. Acesso em: 12 jun. 2021.

HAESBAERT, Rogério. Território e multiterrtorialidade: um debate. Geographia, Rio de Janeiro, v.9, ${ }^{\circ} 17,2007$.

Disponível em: https://periodicos.uff.br/geographia/article/view/13531. Acesso em: 06 set. 2018.

HALL, Stuart. A identidade cultural na pós-modernidade. 10ª ed. Rio de Janeiro: DP\&A, 2005.

JAHNECKA, Luciano. O jeito Xavante de torcer: formação de memórias em uma torcida de futebol. 2010. Dissertação (Mestrado em Educação em Ciências) - Instituto de Ciências Básicas da Saúde, Universidade Federal do Rio Grande do Sul, Porto Alegre, 2010.

KNIJNIK, Jorge Dorfman. A mulher brasileira e o esporte: seu corpo sua história. São Paulo: Mackenzie, 2003.

LOURO, Guacira Lopes. Gênero, sexualidade e educação: uma perspectiva pós-estruturalista. Petrópolis: Vozes, 1997.

MARTINS; Daiane Grillo; KNUTH, Alan Goularte. Manifestações torcedoras e território: configurações das imediações da Arena do Grêmio. Movimento, Porto Alegre, v. 26, e26046, 2020a. Disponível em: https://seer.ufrgs.br/Movimento/article/view/98929. Acesso em: 02 mai. 2021.

MARTINS; Daiane Grillo; KNUTH, Alan Goularte. A composição dos dias de jogos da Arena do Grêmio na vida de moradores e não moradores das imediações do estádio. Fulia, Belo Horizonte, v.5, n. 2, maio-ago 2020b.

Disponível em: https://periodicos.ufmg.br/index.php/fulia/article/view/21822. Acesso em: 02 mai. 2021.

MARTINS, Daiane Grillo; SILVEIRA, Raquel da; FREITAS, Gustavo da Silva. Apontamentos sobre as manifestações do "ser torcedora" do Sport Club São Paulo. Revista Brasileira de Ciências do Esporte, Florianópolis, v. 36, n. 2, supl., p. S182-S196, 2014. Disponível em: http://revista.cbce.org.br/index.php/RBCE/article/view/2126. Acesso em: 20 ago. 2018.

MARTINS, Heloísa Helena de Souza. Metodologia qualitativa de pesquisa. Educação e pesquisa, São Paulo, v. 30, n. 2, p. 289-300, 2004. Disponível em: https://www.revistas.usp.br/ep/article/view/27936/29708. Acesso em: 02 jun. 2017.

NASCIMENTO, Lecir Moreira; DOURADO, Priscila Maria de Souza. Os bastidores da ciência: enfrentamento e superação das pesquisadoras na Universidade Católica de Brasília e o impacto em suas carreiras, família e bem-estar. XV Colóquio Internacional de Gestão Universitária - CIGU: desafios da gestão universitária no século XXI. Mar del Plata - Argentina, 2015. Disponível em: https://repositorio.ufsc.br/xmlui/handle/123456789/136242. Acesso em: 10 fev. 2022. 
SOARES, Guiomar Freitas. Da invisibilidade à cidadania: um estudo sobre as identidades de gênero. In: SEFFNER, Fernando; SOARES, Guiomar Freitas; SILVA, Méri Rosane Santos da; RIBEIRO, Paula Regina Costa. Corpo, gênero e sexualidade: problematizando práticas educativas e culturais. Rio Grande: FURG, 2006. p. 61-67.

VELHO, Gilberto. Observando o familiar. In: NUNES, Edson de Oliveira (org). A Aventura Sociológica. Rio de Janeiro: Zahar Editores, 1978. p. 123-132.

WACQUANT, Löic. Corpo e Alma: notas etnográficas de uma aprendiz de boxe. Rio de Janeiro: Relume Dumará, 2002.

WINKIN, Yves. A nova comunicação: da teoria ao trabalho de campo. Campinas: Papirus, 1998.

\section{NOTAS DE AUTOR}

AGRADECIMENTOS - não se aplica

CONTRIBUIÇÃO DE AUTORIA - não se aplica

FINANCIAMENTO

Pesquisa financiada por bolsa da CAPES.

CONSENTIMENTO DE USO DE IMAGEM - não se aplica

APROVAÇÃO DE COMITÊ DE ÉTICA EM PESQUISA

Aprovação no Comitê de Ética da Faculdade de Medicina da Universidade Federal de Pelotas, sob parecer $\mathrm{n}^{\circ}$ 2.897.136, aprovado em 17 de setembro de 2018 .

\section{CONFLITO DE INTERESSES}

Os autores declaram não haver conflito de interesses.

\section{LICENÇA DE USO}

Os autores cedem à Motrivivência - ISSN 2175-8042 os direitos exclusivos de primeira publicação, com o trabalho simultaneamente licenciado sob a Licença Creative Commons Attribution Non-Comercial ShareAlike (CC BY-NC SA) 4.0 International. Esta licença permite que terceiros remixem, adaptem e criem a partir do trabalho publicado, desde que para fins não comerciais, atribuindo o devido crédito de autoria e publicação inicial neste periódico desde que adotem a mesma licença, compartilhar igual. Os autores têm autorização para assumir contratos adicionais separadamente, para distribuição não exclusiva da versão do trabalho publicada neste periódico (ex.: publicar em repositório institucional, em site pessoal, publicar uma tradução, ou como capítulo de livro), com reconhecimento de autoria e publicação inicial neste periódico, desde que para fins não comerciais e compartilhar com a mesma licença. 


\section{PUBLISHER}

Universidade Federal de Santa Catarina. Programa de Pós-Graduação em Educação Física. LaboMídia - Laboratório e Observatório da Mídia Esportiva. Publicado no Portal de Periódicos UFSC. As ideias expressadas neste artigo são de responsabilidade de seus autores, não representando, necessariamente, a opinião dos editores ou da universidade.

\section{EDITORES}

Mauricio Roberto da Silva, Giovani De Lorenzi Pires, Rogério Santos Pereira.

\section{EDITOR DE SEÇÃO}

Silvan Menezes dos Santos

\section{REVISÃO DO MANUSCRITO E METADADOS}

Juliana Rosario; Keli Barreto Santos.

\section{HISTÓRICO}

Recebido em: 15 de agosto de 2021.

Aprovado em: 13 de outubro de 2021. 